\title{
DIFERENTES NÍVEIS DE CÁLCIO E O DESENVOLVIMENTO DE PLANTAS DE ESTILOSANTES (Stylosanthes guyanensis (AUBL.) SW. CV "COOK")
}

\author{
J.D. RODRIGUES; S.D. RODRIGUES; J.F. PEDRAS; M.E.A. DELACHIAVE; C.S.F. BOARO; \\ E.O. ONO \\ Departamento de Botanica - IB/UNESP - CEP: 18618-000-Botucatu,SP.
}

\begin{abstract}
RESUMO: 0 presente experimento teve como finalidade estudar os efeitos de níveis de cálcio no desenvolvimento de plantas de Stylosanthes guyanensis (Aubl.) Sw. cv "Cook", em sua fase vegetativa, através dos parâmetros que compõem a análise fisiológica de crescimento e de que forma estes parâmetros se alteram, em função dos tratamentos utilizados. Delinearaun-se quatro tratamentos, a saber: T1 (200 mg de cálcio/litro); T2 (133,33 mg de cálcio/litro); T3 (66,66 mg de cálcio/litro); T4 (omisso em cálcio). O experimento foi instalado em cultivo hidropônico, empregando-se soluçāo nutritiva $n^{0} 1$ de Hoagland \& Amon (1950) e conduzido em casa de vegetação. O experimento, inteiramente casualizado, obedeceu ao delineamento de parcelas sub-divididas, considerando-se as cinco coletas, realizadas a intervalos de 14 dias como parcelas, sendo os tratamentos empregados definidos como sub-parcelas. A influência dos diferentes tratamentos, foi avaliada através da área foliar (AF), área foliar específica (AFE), razão de massa foliar (RMF) e razâo de área foliar (RAF). Dos resultados obtidos, pôde-se concluir que plantas de estilosantes, durante a fase de crescimento vegetativo, alcançaram melhor desenvolvimento em niveis de $200 \mathrm{mg}$ de cálcio/litro de solução nutritiva.
\end{abstract}

Descritores: estilosantes, cálcio, analise de crescimento, nutrição mineral

\section{GROWTII OF STYLO PLANTS AS AFFECTED BY CALCIUM IEVEIS (Stylosanthes guyanensis (AUBL.) SW. CV "COOK")}

\begin{abstract}
The influence of calcium levels on the growth of Stylosanthes guyanensis (Aubl.) SW. cv "Cook" plants was studied under the following treatments: T1 (200 mg of calcium/litre); T2 (133.33 mg of calcium/litre); T3 (66.66 $\mathrm{mg}$ of calcium/litre) and T4 (without calcium). The study was carried out in a hydroponic media with Iloagland \& Aruon's number one nutrient solution. The experiment was designed as a completely randomized split-plot design, considering the five samplings performed in 14 day intervals as main plots. The influence of different treatments was evaluated through leaf area (LA), specific leaf area (SLA), leaf weight ratio (LWR), and leaf area ratio (LAR). The results obtained indicated that stylo plants had a better development in the $200 \mathrm{mg}$ of calcium/litre level in nutrient solution.
\end{abstract}

Key Words: stylo plants, calcium, analysis of growth, mineral nutrition.

\section{INTRODUÇÃO}

A análise de crescimento foi definida por MAGALHĀES (1979), como o método que descreve as condições morfofisiológicas da planta em diferentes intervalos de tempo, entre duas amostragens sucessivas e se propõe a acompanhar a dinâmica da produção fotossintética, avaliada através do acúmulo de matéria seca.

Tal definição coincide com o relato de BENINCASA (1988), e mais, a autora refere que a acumulação de material resultante da fotossíntese líquida, passa a ser o aspecto fisiológico para a análise de crescimento. Dessa forma, a pesquisadora define fotossíntese líquida como a diferença entre a bruta, que é aquela resultante da atividade direta dos cloroplastos e o que é consumido pela respiração. De acordo com PEREIRA \& MACHADO (1987), análise quantitativa de crescimento seria o primeiro passo na análise da produção vegetal, requerendo informações referentes à quantidade contida na planta toda $\mathbf{e} o$ tamanho do aparelho fotossintetizante, sendo que tais informações seriam obtidas em intervalos de tempo, durante o ciclo de vida do vegetal.

Embora o material formado por uma cultura, durante o seu crescimento, provenha da fotossíntese, a produção depende do suprimento mineral, embora os mesmos constituam apenas uma pequena proporção da massa seca. Sabe-se que a 
insuficiência ou omissão de um elemento nutricional, interfere na produção final, porém é igualmente desconhecido qual dos parâmetros fisiológicos intermediários fica comprometido, interferindo na produtividade (MILTHORPE \& MOORBY, 1974).

BARRIGA (1979) relatou que a má qualidade das pastagens, associada à baixa fertilidade dos solos, faz com que o rebanho bovino brasileiro apesar de ser, numericamente, um dos maiores do mundo, apresente baixa produtividade. A melhora na produção de forragens, pode ser alcançada através da introdução de leguminosas em pastagens de gramíneas, sendo estas a fonte mais econômica de proteína para os rebanhos (BARRIGA, 1979). O estudo das leguminosas forrageiras no Brasil encontra-se relegado a um plano secundário, quando comparado ao das gramíneas, impedindo a obtenção de leguminosas que possam competir favoravelmente, principalmente quando cultivadas em solos tropicais de baixa fertilidade.

Face ao exposto, percebe-se a importância do Stylosanthes gayanensis (Aubl.) Sw. cv "Cook" como forrageira, entre as leguminosas tropicais, devido a grande disponibilidade no Brasil, à sua capacidade de consorciação com gramíneas, tornando-se alternativa para o aumento da produtividade de pastagens tropicais (WHYTE et al., 1968).

No Brasil, para pastagens são utilizados solos de campos cerrados ou solos rejeitados de outras culturas, que apresentam como limitante baixa fertilidade, com deficiência e desequilíbrio de nutrientes (PEDREIRA, 1973).

A América Latina apresenta deficiência nutricional de cálcio cada vez mais frequente, refletindo baixa produtividade agropecuária (MALAVOLTA et al., 1979). Os mesmos autores enfatizam o estudo do papel desse macronutriente, em função da carência que ocorre em muitas regiōes, além do que a adubação das pastagens por superfosfato, leva à imobilização do cálcio, pelo acido formado na degradação desse fertilizante.

Portanto, considerando-se a importância das leguminosas no enriquecimento protéico das pastagens e o baixo nível de cálcio nos solos onde estas são cultivadas, neste trabalho propõe-se a estudar a influência de níveis desse mineral sobre o desenvolvimento de plantas de Stylosanthes guyanensis (Aubl.) Sw. cv "Cook", leguminosa forrageira muito importante $e$ frequente nas pastagens brasileiras.

\section{MATERIAL E METODOS}

As plantas de Stylosanthes guyanensis (Aubl.) Sw. cv "Cook" foram obtidas à partir de sementes, as quais foram colocadas para germinar em bandejas, tendo como substrato algodão e papel de filtro umedecidos com água desmineralizada. Em seguida, as bandejas foram colocadas em câmara climatizada regulada a $20^{\circ} \mathrm{C}$, até que as radículas apresentassem cerca de $5 \mathrm{~mm}$ de comprimento.

A partir desse estádio, as sementes foram transferidas para bandejas contendo vermiculita $\mathbf{e}$ irrigadas com solução nutritiva $n^{0} 1$ de HOAGLAND \& ARNON (1950), diluída a 1/5, para evitar, nas plântulas, a possibilidade de toxicidade por nutrientes. Com a idade de 10 dias, as plântulas em número de duas, foram colocadas em vasos de plástico de seis litros de volume, contendo solução nutritiva $n^{\circ} 1$ de HOAGLAND \& ARNON (1950), sob arejamento constante e levadas à casa de vegetação.

A fonte de cálcio utilizada, segundo o mesmo autor foi $\mathrm{Ca}\left(\mathrm{NO}_{3}\right)_{2} .4 \mathrm{H}_{2} \mathrm{O}$ P.A., como solução molar, na base de $5 \mathrm{ml}$ dessa solução por litro de solução nutritiva. Esta foi preparada com diferentes níveis de cálcio, definindo-se os seguintes tratamentos: T1 - solução nutritiva contendo $200 \mathrm{mg}$ de cálcio/litro; T2 - solução nutritiva contendo $133,33 \mathrm{mg}$ de cálcio/ litro; T3 solução nutritiva com $66,66 \mathrm{mg}$ de cálcio/litro; T4 - solução nútritiva omissa em cálcio. A concentração de nitrogênio foi mantida constante, equivalente ao encontrado no tratamento $T 1$, ou seja, a solução nutritiva completa utilizada neste experimento.

Para a avaliação do efeito dos diferentes níveis de cálcio sobre o desenvolvimento das plantas de estilosantes, foi realizada a medida da área foliar (AF, em $\mathrm{cm}^{2}$ ), que foi obtida imprimindo-se os contornos das folhas em papel heliográfico, com distribuição de peso e área, o qual permite a impressão das folhas por apresentar pigmentos fotossensiveis, que mediante exposição à luz sofre mudanças de cor. $O$ papel $E$, em seguida, revelado em vapor de hidróxido de amônio, sendo as folhas recortadas e pesadas. Como a relação entre área e peso do papel é conhecida e constante, as folhas tem sua área através do peso (SESTAK et al., 1971; RODRIGUES, 1990). Em cada sub-parcela, a área foliar foi definida, como o somatório de todas as folhas das duas plantas. 
Também foram calculados os seguintes parâmetros fisiológicos da análise de crescimento:

a) área foliar específica (AFE, em $\mathrm{cm}^{2} / \mathrm{g}$ ), cujo inverso reflete a espessura da folha, sendo o componente morfológico e anatômico da RAF, relacionando a superfície com o peso da matéria seca da própria folha (BENINCASA, 1988). O cálculo da AFE, segundo MAGALHÃES (1979), foi definido, como a razão entre a área foliar (AF) e a matéria seca das mesmas (MSF);

b) razão de área foliar (RAF, em $\mathrm{cm}^{2} / \mathrm{g}$ ) que representa a medida da dimensão relativa do aparelho assimilador, servindo como parâmetro apropriado para as avaliaçôes dos efeitos genotípicos, climáticos e do manejo de comunidades vegetais (RODRIGUES, 1982).

Esta expressão é definida como o quociente entre a área foliar (AF) e a matéria seca da planta (MST); c.) razão de massa foliar (RMF, em $\mathrm{g} / \mathrm{g}$ ), definida como a relação entre a matéria seca de folha (MSF) e matéria seca da planta (MST), conforme MAGALHÃES (1979).

Para o cálculo desses três parâmetros fisiológicos da análise de crescimento, além dos dados de área foliar, utilizou-se também dos dados de matéria seca, que foi determinada através de secamento do material vegetal, em estufa com circulação forçada de ar, a $60-70^{\circ} \mathrm{C}$, até este material atingir massa constante (BENINCASA, 1988; RODRIGUES, 1990), o qual foi medido em cada órgão individualmente, isto é, de raiz, caule e folhas. Em cada sub-parcela, a matéria seca foi definida como a soma da matéria seca das duas plantas do vaso. Essas avaliações foram efetuadas nas 5 coletas, realizadas a intervalos de 14 dias, a partir do $10^{\circ}$ dia.

$O$ experimento foi montado num esquema inteiramente casualizado, considerando-seas coletas como parcelas, e os tratamentos como sub-parcelas.

Os resultados obtidos para área foliar foram submetidas a análise de variância (teste $F$ ), onde os graus de liberdade da interação tratamentos por coletas mais os graus de liberdade de tratamentos, foram desdobrados em efeitos de regressão dentro de cada coleta.

Os resultados dos parâmetros fisiológicos estudados não foram analisados estatisticamente, uma vez que não se pode afirmar que essas variáveis, por serem calculadas, obedeçam as pressuposições básicas para a realização da análise de variância (BANZATTO \& KRONKA, 1989).

\section{RESULTADOS E DISCUSSÃO}

\section{1. Área Foliar}

Os resultados obtidos para área foliar (AF), nos quatro níveis de cálcio, estão expressos na TABELA 1. A análise de variância, com desdobramentos em efeitos de regressão, revelou que as duas primeiras coletas não apresentaram significância estatística, para influência dos diferentes níveis de cálcio na área foliar de estilosantes. No entanto, a partir da terceira e até a última coleta, esta significância $(p<0,05)$ se estabelece, de maneira bastante característica, para a componente linear da regressão. Assim, fica estatisticamente comprovado o efeito do cálcio na área foliar, pois à medida que os níveis desse elemento diminuem, ocorre drástica redução nesta medida, sendo os maiores valores obtidos para 0 tratamento T1 (200 mg de cálcio/litro) e os menores para o tratamento $\mathrm{T} 4$, aquele omisso $\mathrm{cm}$ cálcio.

A observação da TABELA 1 mostra, dentro de cada coleta, tendência de influência do cálcio no desenvolvimento da área foliar, mesmo nas duas primeiras, onde o tratamento estatístico não detectou essa influência. Assim, pode-se notar na primeira coleta, diminuição da área foliar, na proporção em que caem os níveis de cálcio. A segunda coleta, revela que o tratamento omisso em cálcio apresentou maiores valores que aqueles $\mathrm{com}$ $66,66 \mathrm{mg}$ de cálcio/litro, apesar de não significativo.

De qualquer forma, mesmo nesta coleta, os tratamentos com níveis maiores de cálcio foram responsáveis pelas maiores áreas foliares, na sequência $T 1$ superior à $T 2$. Nas coletas números três, quatro e cinco, os maiores valores de área foliar foram obtidos no tratamento $\mathrm{T} 1$, declinando os resultados com a queda no teor de cálcio, utilizados para diferenciar os vários tratamentos, sendo os menores valores auferidos no tratamento que não contém cálcio (T4). Deve ser ressaltado que o mais baixo valor de área foliar, durante todo o experimento, à exceção da primeira coleta, foi obtido no tratamento omisso em cálcio, na última coleta.

Os dados existentes na literatura sobre a ação do cálcio na área foliar, mais especificamente, na parte aérea, levando em conta a produção de massa, efeito na morfologia das folhas, tamanho destas, são em grande número, todos destacando ser este mineral, fundamental para a obtenção de 
plantas dotadas de grande área foliar, estabelecendo condições para alta atividade fotossintética, visando a produção de massa foliar. Assim, na omissão de cálcio, a sintomatologia de deformação de folhas, redução do tamanho destas, clorose, diminuição do número de folhas e necrose do limbo verificada por autores como LONERAGAN (1959), BUSSLER (1963), LONERAGAN \& SNOWBALL (1969), COBRA NETO et al. (1971), MALAVOLTA et al. (1976), RODRIGUEZ et al. (1977), GILLI (1977) e ROSOLEM (1980), leva à depreender-se que, na instalação da carência de cálcio, ocorre redução da área foliar. RODRIGUES (1982) observou, em plantas de soja carentes em cálcio, grande diminuição na área foliar, quando comparadas com plantas em tratamento completo. Parece interessante destacar a concordância dos resultados obtidos, com aqueles conseguidos pelos autores citados, mostrando um forte efeito do cálcio na produção de massa da parte aérea, bem como no aumento da área foliar. Deve-se destacar o baixo valor da área foliar obtido na quinta coleta, no tratamento omisso em cálcio, fase final do desenvolvimento vegetativo. Este resultado, recebe confirmação de trabalhos de autores como MILLAWAY \& WIERSHOLM (1979) e PREVEL (1981), os quais relatam ser o cálcio operativo na ligação auxina-receptor; a quinta coleta, possivelmente, seria uma fase crítica do desenvolvimento do estilosantes, quando a planta estaria preparando-se para passar da fase vegetativa para a reprodutiva, portanto um momento de grande desbalanço hormonal. Assim, esse baixo valor seria atribuído, provavelmente, à uma variação brusca no conteúdo auxínico do vegetal, levando à queda das folhas.

\section{2. Área Foliar Específica}

Na Figura 1, estão os resultados obtidos para a área foliar específica (AFE), onde pode-se observar que os maiores valores foram obtidos no nível de $200 \mathrm{mg}$ de cálcio/litro (T1) enquanto que os menores aconteceram no tratamento T2 $(133,33$ $\mathrm{mg}$ de cálcio/litro). Verificando-se a Figura 1, nota-se que os tratamentos com baixo nível de cálcio (T3 $=66,66 \mathrm{mg}$ de cálcio/litro) e o $\mathrm{T} 4$, omisso em cálcio, apresentaram resultados de AFE maiores que $T 2$, apenas inferiores ao $T 1$, sendo que o T3 e T4 praticamente mostraram o mesmo comportamento, com exceção da primeira coleta, onde T4 apresentou maiores valores que T3. Interessante, ao observar a Figura 1, é que a primeira coleta apresentou sempre maiores valores de AFE, em todos os quatro tratamentos de cálcio, quando comparada com as outras quatro coletas.

Os resultados obtidos neste trabalho, não seguem totalmente aqueles relatados pela literatura. Os aqui obtidos, revelam ser a área foliar específica maior na primeira do que nas demais coletas, discordando dos trabalhos de KOLLER et al. (1970), os quais relatam, para soja, pequenos e constantes incrementos neste parâmetro, até cerca de 40 dias após a semeadura, decrescendo até o final do ciclo do vegetal.

Já RODRIGUES (1982), obteve os maiores valores de AFE na primeira coleta, seguindo-se a queda na segunda coleta, acontecendo a seguir incremento nesse parâmetro até a coleta final.

Segundo BENINCASA (1988), o inverso da área foliar específica reflete a espessura da folha, sendo o comportamento morfológico e anatômico da razão de área foliar (RAF), relacionando a superfície com o peso da matéria seca da própria folha. Assim, parece claro, que no início do desenvolvimento, os valores da AFE devam ser maiores, revelando folhas pouco finas, pobre em matéria seca e com baixos valores de área foliar, o que em verdade obteve-se e, portanto, de acordo com o conceito desse parâmetro da análise de crescimento. Orá, é evidente que à medida que a área foliar se desenvolve, ocorre também acúmulo da matéria seca dessas folhas, e como a AFE relaciona a superfície com a massa desse órgão vegetal, a tendência é a queda dos valores deste parâmetro fisiológico, logo após a primeira coleta, para estabilizar-se nas coletas seguintes, conforme pode ser facilmente verificado na Figura 1.

Tais resultados, estão diretamente relacionados com os aumentos da área foliar e da matéria seca de folhas, que ocorrem durante o desenvolvimento do estilosantes. Possivelmente, a expansão da área foliar, geneticamente condicionada, seja inferior ao acúmulo de matéria seca nas próprias folhas, formando órgãos com mais reservas e portanto, mais espessas, à medida que a planta se desenvolve, pelo menos até aos 80 dias de idade.

A observação da Figura 1, ainda mostra um comportamento fisiológico, que evidencia uma tendência do efeito dos diferentes tratamentos de cálcio, nos resultados para área foliar específica. Assim, o tratamento T1, com os maiores níveis de cálcio, apresentou altos valores de AFE, mostrando 
folhas pouco espessas, provavelmente em função da velocidade de translocação, que em plantas supridas de cálcio seria muito intensa enquanto aquelas carentes sofreriam restrições neste processo fisiológico (JOHAM, 1957; GALLAHER et al., 1976; MILLAWAY \& WIERSHOLM, 1979).

A queda dos valores de AFE, obtida no tratamento $T 2$, concentração $1 / 3$ menor de cálcio do que $\mathrm{T} 1$, reflete um expressivo aumento da matéria seca das folhas, relativamente à expansão foliar, medida pela área, mostrando folhas mais espessas, inclusive com reservas de carboidratos. Estes, por sua vez, podem não ter sido translocados das folhas, possivelmente, pelo efeito depressivo dos baixos níveis de cálcio, característico deste tratamento, no transporte de solutos orgânicos.

O tratamento T3 $(66,66 \mathrm{mg}$ de cálcio/litro) e T4 (sem cálcio), apresentaram resultados de AFE pouco superiores ao $\mathrm{T} 2$, isto em consequência da maior queda no acúmulo de matéria seca foliar, relativamente à diminuição que a área das folhas sofre nestes tratamentos.

Mais uma vez, demonstra-se ser o cálcio, quando ausente ou em níveis muito baixos, provavelmente mais crítico para a expansão foliar, do que para a síntese de matéria seca, como enfatizam JONES \& LUNT (1967) ao destacarem, entre outros, o papel do cálcio na formação de paredes e placas celulares, formando pectatos. Isto, afora sua ação no alongamento celular e na integridade de membranas, ao ligar-se às fosfolipases, ativando pelo menos uma dezena de enzimas.

\section{Razāo de Massa Foliar}

A razão de massa foliar (RMF), que reflete a relação do aparelho fotossintetizante $\mathrm{em}$ relação à biomassa vegetal total, tem seus resultados apresentados na Figura 2, onde se verifica uma tendência genérica para a redução desse valor, para todos os tratamentos, à medida que o ciclo do vegetal se desenvolve, à exceção de picos eventuais ocorridos na segunda e terceira coletas. ASCÊNCIO \& FARGAS (1973) relataram para feijão cultivado em solução nutritiva $n^{\circ} 2$ de HOAGLAND \& ARNON (1950), que a razão de massa foliar era elevada nas primeiras semanas de crescimento, diminuindo até o final do ciclo, ajustando-se a uma função linear.

LUGG \& SINCLAIR (1980) demonstraram que a RMF decresce nas fases de aumento da área foliar, ou seja, na fase de desenvolvimento vegetativo. Portanto, os dados obtidos para razão de massa foliar coincidem com os da literatura, isto $\hat{\epsilon}$, obedecem ao comportamento esperado, pois inicialmente ha proliferação foliar, levando a um aumento de peso, em detrimento ao acréscimo no restante dos órgãos do estilosantes.

À medida que as folhas atingem sua fase madura, começa a haver decréscimo na RMF, ou seja, há direcionamento de compostos fotossintetizados para outras regiōes vegetais (KOLLER et al., 1970; LUGG \& SINCLAIR, 1980).

Quanto aos efeitos do cálcio nos valores de razão de massa foliar, dentro de cada coleta, a observação da Figura 2 mostra que na maioria das coletas, excetuando-se a segunda e a quarta, o tratamento com o maior nível em cálcio (T1), foi o que apresentou os valores superiores de RMF.

$\mathrm{Na}$ segunda, o maior resultado foi obtido no tratamento T2. Verificando-se a Figura 2, nota-se que em cada coleta, a ação do cálcio, nos valores de RMF apresentou resultados distintos.

Assim, na $1^{\text {a }}$ coleta a menor RMF ocorreu em meio omisso em cálcio, enquanto que na segunda, este tratamento foi o que apresentou os maiores valores.

$\mathrm{Na}$ terceira coleta, o tratamento $\mathrm{T} 4$ só foi inferior ao $\mathrm{T} 1$; já para a quarta, os menores valores de RMF foram obtidos nos tratamentos com baixos níveis de cálcio (T3) e na sua ausência (T4).

A quinta coleta foi a de comportamento mais linear, ocorrendo decréscimo na razão de massa foliar com a queda do nível de cálcio, caracterizado pelos tratamentos empregados.

Dessa maneira, os resultados, no tocante à ação do cálcio sobre a razão de massa foliar, são conflitantes com aqueles encontrados na literatura. No entanto, estes não se referem à estilosantes e só consideram tratamentos com presença ou ausência de cálcio, não se referindo às dosagens intermediárias desse elemento mineral.

RODRIGUES (1982) encontrou maiores valores de RMF no tratamento omisso em cálcio, quando comparado com o completo, trabalhando com plantas de soja; em algodão carente em cálcio, JOHAM (1957) relatou acúmulo de carboidratos nas folhas, enquanto GALLAHER et al. (1976), também o fizeram para soja e amendoim.

Para RODRIGUES (1982), é perfeitamente esperado valores altos de RMF na carência de cálcio, na fase vegetativa de plantas de soja, possivelmente, segundo a autora, devido à ação interferente desse mineral na translocação. 
TABELA 1 - Resultados médios obtidos para área foliar, expressos em $\mathrm{cm}^{2}$.

\begin{tabular}{ccccccc}
\hline \multirow{2}{*}{ Cálcio } & \multicolumn{6}{c}{ Coletas } \\
\cline { 2 - 7 } mg/l & I & II & III & IV & V & Médias \\
\hline 200,00 & 49,10 & 191,62 & 396,59 & 629,32 & 656,09 & 384,54 \\
133,33 & 30,03 & 173,48 & 287,92 & 505,63 & 593,58 & 318,13 \\
66,66 & 21,10 & 122,91 & 219,79 & 256,37 & 327,33 & 189,50 \\
0,00 & 17,70 & 138,41 & 175,81 & 210,86 & 79,08 & 124,40 \\
\hline F & ns & ns & L $^{-}$ & L & L'- & \\
\hline \hline
\end{tabular}

CV $(\mathrm{a}-$ Coletas $)=31,4 \% ; \quad$ CV $(\mathrm{b}-$ Tratamentos $)=40,2 \%$

L* Regressão Linear significativa (* $=p<0,05$;

$* *=p<0,01)$.

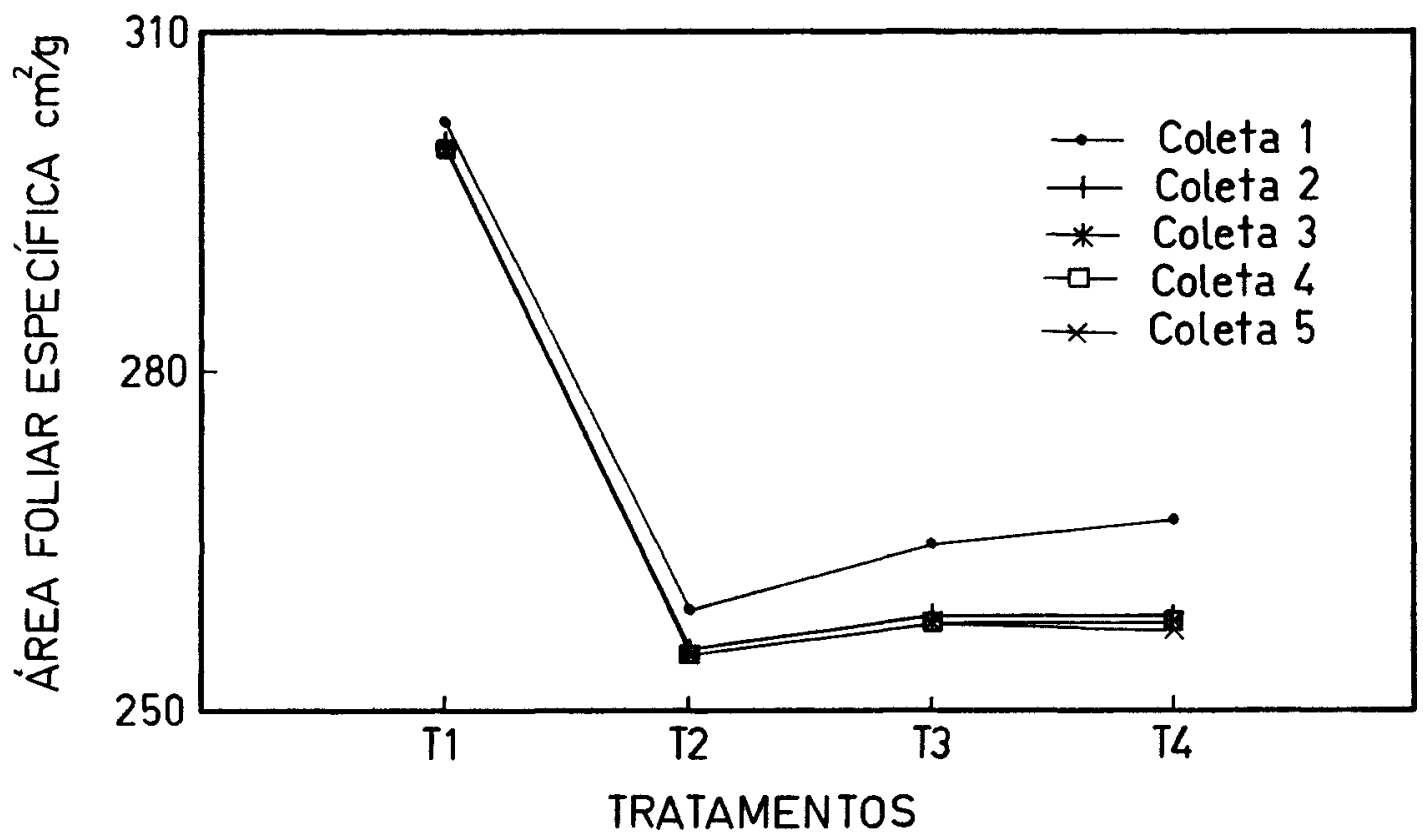

Figura 1 - Valores médios obtidos para área foliar específica $\left(\mathrm{em} \mathrm{cm}^{2} / \mathrm{g}\right)$, de plantas de estilosantes, submetidas à diferentes níveis de cálcio. 


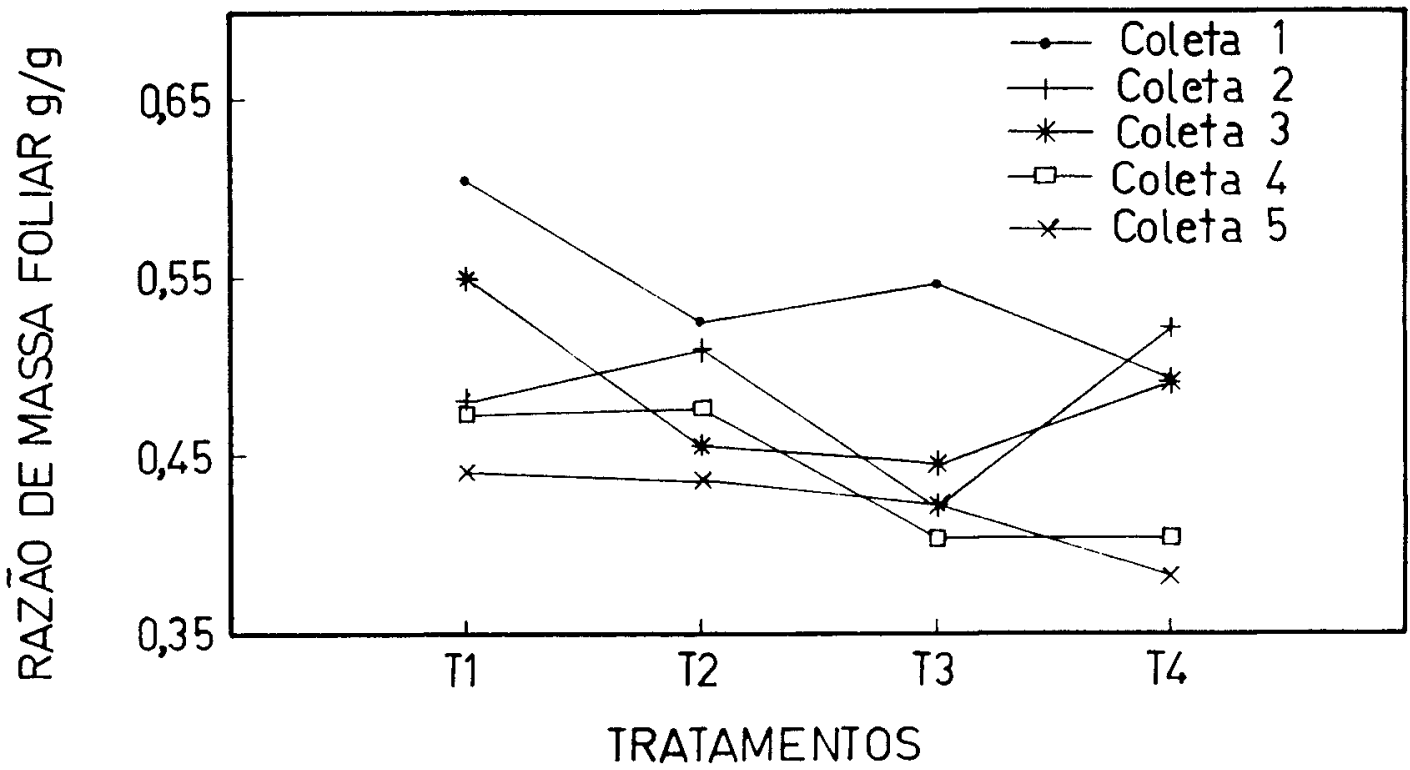

Figura 2 - Valores médios obtidos para razão de massa foliar (em $\mathrm{g} / \mathrm{g}$ ), de plantas de estilosantes, submetidas à diferentes níveis de cálcio.

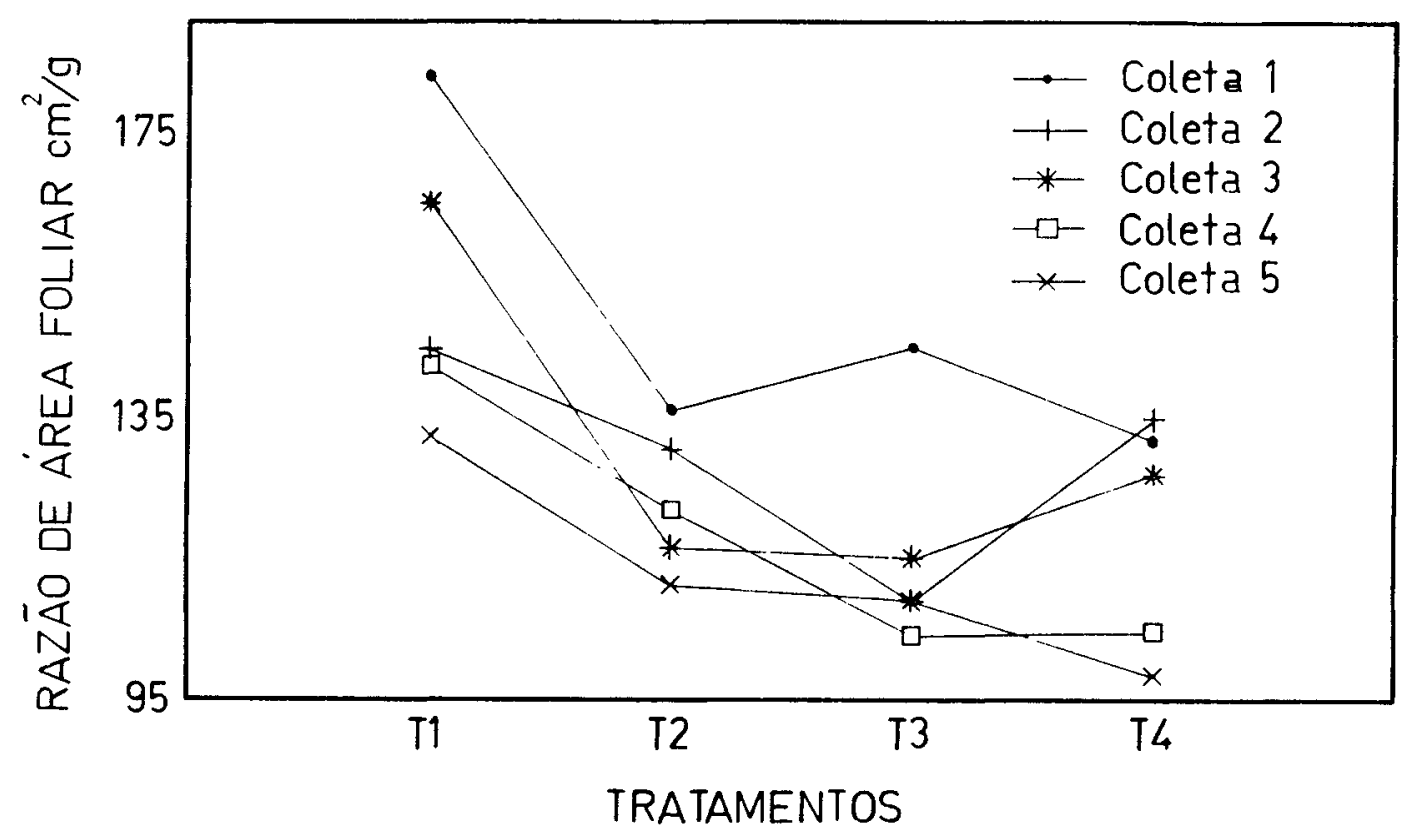

Figura 3 - Valores médios obtidos para razão de área foliar $\left(\mathrm{em}^{\mathrm{cm}} / \mathrm{g}\right)$, de plantas de estilosantes, submetidas à diferentes níveis de cálcio. 


\section{Razão de Área Foliar}

Os resultados obtidos para a razão de área foliar (RAF) encontram-se na Figura 3. Segundo RODRIGUES (1982), tal parâmetro representa a dimensão relativa do aparelho fotossintético, sendo inclusive apropriado à avaliação dos efeitos genotípicos, climáticos e de manejo de comunidades vegetais.

A Figura 3, mostra um decréscimo na razão de área foliar, com a idade da planta, dentro do periodo experimental, para todos os tratamentos utilizados. Evidentemente existem algumas exceções, dentro de cada coleta, que apresentam resultados que fogem à esta tendência, mas que são eventuais e devidos, possivelmente, à fatores que influenciaram também a matéria seca total e a área foliar. Assim, existem picos de RAF, representados pelo tratamento $\mathrm{T} 1$ na $3^{\mathrm{a}}$ coleta, maior que na segunda coleta, bem como valores maiores de RAF no tratamento $\mathrm{T} 4$, omisso em cálcio, para a segunda coleta, relativamente à primeira. A RAF, na quinta coleta é superior à da quarta, quando considerado o tratamento $T 3$.

Logo, a tendência geral é a diminuição da RAF durante o desenvolvimento do estilosantes, em todos os tratamentos. Estes resultados, concordam com aqueles obtidos em soja por KOLLER et al. (1970), SANTOS FILHO (1979) e RODRIGUES (1982). BOARO (1986), trabalhando com feijão, em solução nutritiva $n^{\circ} 2$ de HOAGLAND \& ARNON (1950), também obteve diminuição da RAF durante o desenvolvimento dessas plantas.

A observação do efeito dos diferentes tratamentos de cálcio nos valores da razão de área foliar, dentro de cada coleta, pode ser efetuada através da Figura 3 , onde verifica-se as curvas que representam o comportamento fisiológico das plantas de estilosantes, relativamente à este parâmetro fisiológico. Constata-se pois, que os maiores valores de RAF sempre foram obtidos no tratamento T1 (200 $\mathrm{mg}$ de cálcio/litro), independente da coleta. Os menores valores de RAF não seguiram tendência tão definitiva, com baixo nível de cálcio ( $\mathrm{T} 3=66,66 \mathrm{mg}$ de cálcio/litro) ou omissão deste mineral (T4), variando apenas a coleta. Assim, T4 apresentou os menores resultados de RAF na primeira e quinta coletas, enquanto que para a segunda, terceira e quarta, o tratamento T3 foi aquele em que a RAF foi menor.

De qualquer maneira, parece clara uma tendência em estilosantes, pelos resultados obtidos, de que em níveis normais de cálcio (T1) os valores de razão de área foliar são superiores àqueles quando as plantas sofrem restrições no fornecimento de cálcio, mesmo quando pouco severo como acontece com o tratamento T2. Logo, fica evidente a influência do mineral nos valores de RAF e sendo esta uma medida da dimensão relativa do aparelho assimilador, a importância desse nutriente evidencia-se, através da sua ação na eficiência do aparelho fotossintético.

Tal linha de raciocínio recebe comprovação, em trabalhos como os de ASCÊNCIO \& FARGAS (1973), que para feijão, concluíram ser a RAF um dos índices de crescimento que melhor refletem as condições de produtividade e eficiência do sistema fotossintético dessa planta. WALLACE \& MURGER (1965), realizando análise de crescimento de feijão, observaram que os cultivares mais produtivos, apresentaram maiores valores de área foliar e de razão de área foliar, sendo que em alguns deles, a taxa de crescimento relativo foi acompanhada de razão de área foliar mais elevada, sugerindo ser este o principal fator responsavel por diferenças nesta taxa.

\section{CONCLUSÃo}

Nas condições estudadas as plantas de Stylosanthes gayanensis (Aubl.) Sw. cv "Cook", durante a fase de crescimento vegetativo, alcançaram melhor desenvolvimento, traduzidos por maiores valores de AF, AFE, RMF e RAF, em níveis de $200 \mathrm{mg}$ de cálcio/litro de solução nutritiva, mostrando-se exigente ao fornecimento desse mineral.

\section{REFERÊNCIAS BIBLIOGRAFICAS}

ASCÊNCIO, J.; FARGAS, J.E. Analisis del crecimiento del frijol (Phaseolus vulgaris L. var. "Turrialba-4") cultivado en la solucion nutritiva. Turrialba, San Jose, v.23, p.420-428, 1973.

BANZATTO, D.A.; KRONKA, S. do N. Experimentação agrícola. Jaboticabal, FUNEP, 1989. 247p.

BARRIGA, J.P. Autoecologia de Stylosanthes humilis HBS: avaliação da viabilidade morfológica e estudos da biologia da semente. Piracicaba, 1979. Dissertação (Mestrado) - Escola Superior de Agricultura "Luiz de Queiroz", Universidade de São Paulo. 
BENINCASA, M.M.P. Analise de crescimento de plantas; noções básicas. Jaboticabal, FUNEP, 1988. $42 \mathrm{p}$.

BOARO, C.S.F. Influência da variação dos níveis de magnésio sobre o desenvolvimento do feijoeiro (Phaseolus vulgaris L. cv "Carioca"), em cultivo hidropônico. Botucatu, 1986. Dissertaçāo (Mestrado) - Universidade Estadual Paulista Prof. Júlio Mesquita Filho.

BUSSLER, $W$. The development of calcium deficiency symptoms. Zeitschrift für Pflanzenernahring und Bodenkunde, Weinheim, v.100, p.53-58, 1963.

COBRA NETO, A.; ACCORSI, W.R.; MALAVOLTA, E. Estudos sobre a nutrição do feijoeiro (Phaseolus vulgaris L. var. Roxinho). Anais da Escola Superior de Agricultura "Luiz de Queiroz", Piracicaba, v.28, p.257-273, 1971

GALLAHER, R.N.; BROWN, R.H.; ASHLEY, D.A.; JONES Jr., J.B. Photosynthesis and ${ }^{14} \mathrm{CO}_{2}$ photosynthate translocations from calcium-deficien leaves of crops. Crop Science, Madison, v.16, p.116-119, 1976

GILLI, G. Disorders morphologiques, histologiques et chimiques provoquis par des carences minerales chez Chrysanthemum morifolium. Annales Agronomiques, Paris, v.16, p.116-119, 1977.

HOAGLAND, D.R.; ARNON, D.I. The water method for growing plants without soil. Berkeley: College of Agriculture of the University of California, 1950,32p. (Circular, 343)

JOHAM, H.E. Carbohydrate distribuition as affected by calcium deficiency in cotton. Plant Physiology, Bethesda, v.32, p.113-117, 1957.

JONES, R.G.W.; LUNT, O.R. The function of calcium in plants. Botanical Review, Bronx, v.33, p.407-426, 1967.

KOLLER, H.R.; NYQUIST, W.E.; CHORUSH, I.S. Growth analysis of a soybean comunity. Crop Science, Madison, v.10, p.407-412, 1970.

LONERAGAN, J.F. Calcium in the nitrogen metabolism of subterranean clover. Australian Journal of Biological Science, East Melbourne, v.12, p.26-39, 1959.

LONERAGAN, J.F.; SNWOBALL, K. Calcium requirement of plants. Australian Journal of Agricultural Research, East Melbourne, v.20, p.465-478, 1969.
LUGG, D.G.; SINCLAIR, T.R. Seasonal changes in morphology and anatomy of field grown soybean leaves. Crop Science, Madison, v.20, p.191-196, 1980 .

MAGALHÃES, A.C.N. Análise quantitativa de crescimento. In: FERRI, M.G. (Coord.). Fisiologia Vegetal. São Paulo, EPU/EDUSP, 1979. p.331-350.

MALAVOLTA, E.; CHAVES, I.; TONIN, G.S.; SOUZA, A.F. Deficiências de macronutrientes na soja (Glycine max L. Merrill, var. IAC-2). Anais da Escola Superior de Agricultura "Luiz de Queiroz", Piracicaba, v.33, p.471-477, 1976.

MALAVOLTA, E.; DANTAS, J.P.; MORIAS, R.S.; NOGUEIRA, F.D. Calcium problems in Latin America. Communications in Soil Science and Plant Analysis, New York, v.10, p.29-40, 1979.

MILLAWAY, R.M.; WIERSHOLM, L. Calcium and methabolic disorders. Communications of Soil Science Plant and Analysis, New York, v.10, p.1-28. 1979

MILTHORPE, F.L.; MOORBY, J. An introduction to crop physiology. Cambridge: Cambridge University, 1974. 201p

PEDREIRA, J.V.S. Crescimento de leguminosas forrageiras. Revista Brasileira de Zootecnia, Viçosa, v.2, p.27-33, 1973

PEREIRA, A.R.; MACHADO, E.C. Análise quantitativa de comunidades vegetais. Campinas: Instituto Agronômico, 1987. 33p. (IAC. Boletim técnico, 114).

PREVEL, P.M. Papel que desempenam los minerales en los vegetales. Revista de la Potassa, Berne, v.1, p.1-6, 1981 .

RODRIGUES, J.R. Influência de diferentes níveis de cálcio, sobre o desenvolvimento de plantas de estilosantes (Stylosanthes gityanensis (Aubl.) Sw. cv "Cook"), em cultivo hidropônico. Botucatu, 1990 Tese (Livre-Docência) - Universidade Estadual Paulista Prof. Júlio de Mesquita Filho.

RODRIGUES, S.D. Análise de crescimento de plantas de soja (Glycine max (L.) Merril) submetidas à carências nutricionais. Rio Claro, 1982. Dissertação (Mestrado) - Universidade Estadual Paulista Prof. Júlio de Mesquita Filho.

RODRIGUEZ, S.J.; CIBES, H.R.; GONZALEZ IBANES, J. Some nutrient deficiency symptomes displayed by Dracaena deremensis "Warneckii" under 
greenhouse conditions and their subsequent effects on leaf nutrient content. Journal of Agriculture. University of Puerto Rico, Puerto Rico, v.61, p.406-464, 1977.

ROSOLEM, C.A. Nutrição mineral e adubação da soja. Piracicaba: POTAFOS, 1980. 80p. (POTAFOS. Boletim Técnico, 6).

SANTOS FILHO, B.G.; MADRUGA, L.A.N.; PETERS, J.A.; FARIAS, C.A. Análise de crescimento de duas linhagens de soja (Glycine max (L.) Merrill), em Pelotas, R.S. In: SEMINÁRIO NACIONAL DE PESQUISA DA SOJA, 1., 1978, Londrina. Anais... Londrina: EMBRAPA, Centro Nacional de Pesquisa de Soja, 1979. p.347-361.

SESTÁK, Z.; CATSKY, J.; JARVIS, P.G. Assessment of leaf área and other assimilatory plant surfaces. In: ed. Plant Photosynthetic production: manual of methods. The Hague: Dr. W. Junk, 1971. cap.14, p.517-555.
WALLACE, D.H.; MUNGER, H.M. Studies of the physiological basis for yield differences. I. Growth analysis of six dry bean varieties. Crop Science, Madison, v.5, p.343-348, 1965.

WHYTE, R.O.; NILSSON-LEISSNER, G.; TRAMBLE, H.C. Las leguminosas en la agricultura. Belgrado: FAO, 1968. 405p. (FAO. Estudios agropecuarios, 21).

Trabalho enviado para publicação em 09.10 .92 Trabalho aceito para publicação em 10.03 .93 